\title{
O PARLAMENTO DOS INVISÍVEIS
}

\author{
Renan B. Dantas ${ }^{1}$ \\ Bárbara F. Estevanato ${ }^{2}$
}

\begin{abstract}
RESUMO: No decorrer da história é possível observar que diversas desigualdades se estabeleceram nas condições linguísticas, levando boa parte dos indivíduos ao confinamento da fala, sendo silenciados nos assuntos referentes à organização da vida social, política e econômica. Partindo desta perspectiva, o ensaio de Pierre Rosanvallon, O Parlamento dos invisíveis, que expõe o projeto "Raconter La Vie", torna-se leitura imprescindível, uma vez que o autor tem como objetivo abrir um espaço para que uma multiplicidade de existências e de experiências ignoradas tenham suas trajetórias narradas e levadas em conta, florescendo um movimento social fundado na interação e na troca. Tendo esse horizonte, o livro permite a reflexão sobre a necessidade de se abrir espaços alternativos de transformação que ampliem as formas de representação para que os "invisíveis" possam ser representados e se representem, tendo a oportunidade de participar de um lugar de formação de consciência social.
\end{abstract}

PALAVRAS-CHAVE: Parlamento; Invisíveis; Vozes; Democracia.

\section{THE PARLIAMENT OF THE INVISIBLES}

\begin{abstract}
It has been observed throughout history that various inequalities have been established in linguistic conditions, leading many of the individuals to confinement of speech, being silenced in matters relating to the organization of social, political and economic life. From this perspective, it becomes essential to know the Pierre Rosanvallon's

\footnotetext{
1 Mestrando em Antropologia Social pela Universidade Estadual de Campinas. E-mail: renan_ dantas28@hotmail.com.

2 Graduanda em Ciências Sociais pela Universidade Estadual de Campinas. E-mail: bfestevanato@gmail.com.
} 
essay Parliament of the Invisibles, which exposes the project "Raconter La Vie", in which it aims to open a space so that a multiplicity of ignored existences and experiences have their trajectories narrated and taken into account, flowering a social movement based on interaction and exchange. Therefore, the book allows the reflection of the need to open up alternative spaces of transformation that amplify the forms of representation so that the "invisibles" can be represented and represent themselves, having the opportunity to participate in a place of formation of social conscience.

KEYWORDS: Parliament; Invisible; Voices; Democracy.

Uma das principais características ontológicas do ser humano é a capacidade de comunicação. Por meio da voz é possível estabelecer uma narrativa capaz de transmitir e de definir as condições culturais e sociais. Porém, no decorrer da história, observa-se que diversas desigualdades se estabeleceram nas condições linguísticas, transformando boa parte dos dominados em indivíduos fadados ao silêncio e ao confinamento profundo da fala. Além disso, há um outro movimento no qual as pessoas se acostumam cada vez mais a ignorar vozes e assumir que elas não interessam para a organização das formas da vida social, política e econômica. ${ }^{3}$ Tendo em vista esse horizonte, abrir espaços para dar vozes às pessoas de diversas maneiras é indispensável para criar legitimidade para a democracia. Conforme indica Couldry (2010), construir alternativas políticas que dão atenção aos processos narrativos é uma via de reconhecimento da capacidade das pessoas para cooperação social, ou seja, uma alternativa para articular aspectos da vida humana às questões envolvendo justiça social, o que pode ser capaz de estabelecer novas diretrizes democráticas.

Diante dessas perspectivas, torna-se fundamental conhecer $O$ Parlamento dos Invisiveis (2017), de Pierre Rosanvallon, um ensaio que expõe as ambições do projeto "Raconter La Vie". Este projeto tem como objetivo construir um verdadeiro "Parlamento dos Invisíveis", dando espaço para que uma multiplicidade de existências e experiências ignoradas tenham suas trajetórias narradas e levadas em conta, florescendo um movimento social fundado na interação e na troca. Seu gênero textual se assemelha a

\footnotetext{
${ }^{3}$ Uma distribuição desigual de recursos narrativos representa uma negação da voz, podendo então ser considerado uma forma de controle e profunda opressão.
} 
de um manifesto. Pois, a partir de áreas como a História, a Sociologia, e a Ciência Política, com amparo da Literatura, o projeto defende um espaço de pluralidade e representação do social e do político.

Seu autor, Pierre Rosanvallon, é historiador, sociólogo e politólogo, e ocupa desde 2001 a cátedra de História Moderna e Contemporânea do Político no Collège de France. Além disso, é diretor da Escola de Altos Estudos em Ciências Sociais. Seus trabalhos recentes problematizam questões sobre a democracia contemporânea e a história do modelo político francês, além de discutir temas como desigualdades e justiça social. Rosanvallon também é membro fundador do grupo La République des idées, que tem como objetivo publicar livros que discutem uma refundação teórica da vida intelectual francesa e europeia. Considerado um dos principais "historiadores da democracia", já visitou duas universidades brasileiras para debater os rumos da democracia e discutir questões ligadas à corrupção e à representação nas metamorfoses contemporâneas. No Brasil, encontra-se publicado, além de O Parlamento dos Invisiveis, os livros: Por uma história do Político (2010) e Democracia Inacabada (2018).

Sobre O Parlamento dos Invisiveis, publicado originalmente em 2014, vale observar de início que ele tem como universo empírico de observação o contexto francês, e é dividido em três partes. A primeira, intitulada "Uma sociedade em busca de si mesma", expõe os objetivos e a justificativa do trabalho de Rosanvallon. A segunda, "História de uma preocupação", informa o enquadramento teórico-metodológico construído pelo autor no recorte de seu projeto, e menciona algumas de suas principais fontes de inspiração. E a terceira parte, "As formas de um projeto: as vias plurais do conhecimento do mundo", analisa os resultados do projeto, com agudas reflexões sobre a democracia contemporânea.

Sobre a primeira parte, chama atenção o quadro social de "deriva da democracia" montado pelo autor, um quadro que é associado às crises da ordem econômica e do desencantamento e medo do futuro, num país que "não se sente escutado". Nesse sentido, Rosanvallon se refere principalmente aos excluídos do mundo legal, dominado pelos governantes, pelas instituições e pela mídia. Mais especificamente, a análise recai sobre os pobres, precarizados de várias formas, migrantes, mulheres, 
LGBTs etc. Segundo o autor, alguns destes "excluídos" já se formaram em certa tradição reivindicativa ou no acesso à mídia, mas outros estão totalmente "à espera de reconhecimento". E aqui coloca-se uma pergunta fundamental: reconhecimento de quem? Dialogando com essa questão, o autor sugere que é papel da democracia "escutar as vozes dos mais fracos", porém, como sabemos, o que ela tem feito é negligenciar suas existências, colocando em risco não só a dignidade dos indivíduos como a própria integridade da democracia. A falta de escuta de certos setores sociais, para Rosanvallon, contribui para o esvaziamento da noção do real e para o desencanto social do político, manifestado em movimentos populistas e antipolíticos que se dizem porta-vozes dos subalternos.

Argumentando ser necessária uma reforma na maneira como a sociedade é representada, o autor disserta sobre as causas da conjuntura atual de "má representação". A seu ver, parte desta crise representativa surge a partir do próprio sistema político partidário, focado mais na "conquista e exercício do poder do que na representação da sociedade". A representação política da sociedade, em sua perspectiva, é dificultada basicamente por dois fatores: primeiro, devido ao fato de as eleições não cumprem de maneira sobreposta sua dupla função de escolher os governantes e, ao mesmo tempo, transmitir as expectativas dos eleitores. E, um segundo fator, diz respeito à própria natureza da modernidade democrática, atravessada pela contradição de pretender, de um lado, "colocar o povo, como soberano coletivo, no posto de comando" e, de outro, sacralizar "o indivíduo, pois é a partir da valorização da sua autonomia e de seus direitos que se constitui o ideal moderno de igualdade" (ROSANVALLON, 2017, pp.16-17). Este processo, ainda de acordo com o autor, reduz a visibilidade de alguns, pois coloca todos num patamar de igualdade, uma óbvia falácia.

Disso decorre uma "sociedade ilegível", em crise devido à ruptura entre o político (povo) e o sociológico (indivíduo). As mudanças dessa sociedade e de sua forma econômica capitalista alteraram, segundo o autor, a estrutura de classes, borrando suas distinções, de tal maneira que as desigualdades se tornam individualizadas. Tais desigualdades decorrem tanto de situações individuais por natureza, quanto de condições sociais como gênero, origem, religião ou outras. Para Rosanvallon, o individualismo 
constitutivo da sociedade moderna, caracterizado por uma singularidade, não oferece um ponto de encontro coletivo, sendo essa a grande questão da modernidade desde a Revolução Industrial. Ainda que encontremos, no decorrer do desenvolvimento do capitalismo, laços de solidez coletiva - por meio, por exemplo, do fenômeno das classes operárias -, esses laços estão cada vez mais escassos, devido às novas dinâmicas de organização da vida social e do trabalho, que incentivam o reconhecimento e o sucesso por meio da individualidade. Assim, cada vez menos as pessoas compartilham entre si suas condições de classe, levando a uma dinâmica de desigualdade, que perpetua uma invisibilidade e ilegibilidade social.

Por isso, para o autor, surge uma nova era, a do "individualismo de singularidade", fenômeno ligado ao fato de que, agora, os indivíduos são determinados tanto por sua história pessoal como por suas condições de existência. O Indivíduo-história-singularidade se sobrepôs, de acordo com Rosanvallon, ao indivíduo-condição-grupo, e isso conduz a novas expectativas frente à democracia. A democracia como uma forma social de um "individualismo de singularidade" acrescenta ao direito de ser igual aos outros, o direito de ser único, de ter reconhecido o seu "valor". Diante disso, Rosanvallon considera a problemática social da invisibilidade se remetendo, "portanto, a dois fenômenos cujos efeitos se sobrepõem sem se confundir: de um lado, o esquecimento, a relegação, a negligência, e de outro, a ilegibilidade" (ROSANVALLON, 2017, p. 24).

O projeto "Raconter La Vie" responde justamente a este contexto, motivado por uma ambição democrática de compor uma representaçãonarração, uma forma democrática que permite o reconhecimento e a produção de conhecimento emancipatório. Rosanvallon fala em "dar a palavra, tornar visível - isso é, com efeito, ajudar os indivíduos a se mobilizar, a resistir à ordem existente e a melhor conduzir sua existência""4 (ROSANVALLON, 2017, p. 25), para chegar a uma democracia narrativa, que se autorrepresenta, torna-se mais participativa (indo além do processo eleitoral) e deliberativa, a partir do fomento do debate entre seus cidadãos.

\footnotetext{
${ }^{4}$ É importante mencionar que colocar a narrativa das pessoas como um valor estabelece um processo que elas deem conta de suas vidas, de suas condições e da realidade do mundo que vivem (COULDRY, 2010).
} 
O autor propõe com este debate que a democracia deixe de ser apenas um regime político e se torne de fato uma forma de sociedade. É neste sentido que ele conceitua a noção de democracia narrativa, compreendendo que quanto mais visibilidade e legibilidade, mais a sociedade se torna bem governável e reformável. Uma sociedade quando é "má representada”, por outro lado, torna-se assolada pela passividade e pelo medo, prejudicando a visão da realidade. ${ }^{5}$ Dentro deste diagnóstico, observamos que "Ranconter La Vie" é um projeto moral e social, visando tirar pessoas da invisibilidade e permitindo a produção de um conhecimento que as liguem entre si, pois quando indivíduos se ignoram, não há uma intercompreensão e a vida social se torna diminuída.

A segunda parte do livro oferece um enquadramento teóricometodológico para o referido projeto. Partindo de uma discussão teórica sobre representação social, o autor recorre à História para observar os momentos de "consistência da democracia" e, assim, dar vozes e rostos ao povo soberano. Rosanvallon cita alguns exemplos, entre eles a organização política do mundo operário no século XIX. Naquele contexto, antes mesmo do sufrágio, essa organização encontrou, por meio dos jornais, uma alternativa à falta de representação institucional para difundir as realidades do trabalho. Ou seja, pelo meio impresso, os operários forjaram um modo de falar por eles mesmos.

Outras formas de expressão como a música, a poesia e a literatura de origem popular também foram utilizadas para dar vozes aos trabalhadores, permitindo o entendimento da palavra "representação" como "compreensão e expressão de si”. De modo mais preciso, poetas operários passaram a ser as "vozes dos de baixo", e "tiveram como

\footnotetext{
${ }^{5}$ Para ampliarmos a discussão podemos pensar em casos envolvendo crise de representação e como estas geram distorções da realidade. Por exemplo, o psicanalista político Tales Ab’Saber, discutindo como os discursos nas manifestações pró-impeachment de Dilma Rousseff - que estavam ligados à má representação da sociedade brasileira - levavam a uma realidade distorcida, recorre ao conceito psicanalítico "alucinose", de Bion, cujo significado pode ser resumido nos seguintes termos: "distorção efetiva da capacidade de pensar fundada na necessidade de saturar a realidade com desejos que não suportam frustração, bem como no impacto corrosivo dos mecanismos psíquicos ligados ao ódio sobre o próprio pensamento" (AB’SABER, 2018, p. 129).
} 
obsessão comum dar a palavra a todos proletários ignorados, que a sociedade tratava politicamente como menores e socialmente como párias" (ROSANVALLON, 2017, p. 39). Com o propósito de fazer os mudos falarem, os poetas se tornaram porta-vozes da massa anônima, trazendo legibilidade e compreensão à realidade. O poeta, assim, exercia um papel político semelhante à de um deputado, não pelo espírito de celebridade, mas por carregar as noções de representação e de expressão.

Do mesmo modo, a literatura foi fundamental no contexto de efervescência política da França. Obras dedicadas a "decifrar a França" passaram a ser publicadas abordando os costumes sociais, políticos e culturais, bem como as atividades econômicas. Essas obras retratavam tanto as margens sociais - como os contrabandistas, mendigos e prostitutas - quanto as classes dominantes, que eram figuradas a partir de seus estilos de vida e hábitos. Nesse mesmo período, convém lembrar que teve início o entusiasmo pela Estatística, que permitia a análise das ações governamentais e a aferição da sinceridade do regime representativo. Dentro da mesma lógica literária de "autoanálise" e dos estudos de estatística, o projeto "Ranconter La Vie" também se engaja pela decifração do social.

Nessa empreitada pela "representação", Rosanvallon lembra como o romance e a pesquisa adquiriram papéis destacados. A partir de romances da sociedade, escritores na França, na Inglaterra e nos Estados Unidos se apresentaram desejosos em conhecer a sociedade e descrever em suas obras aquilo que liga o indivíduo ao coletivo. Seus objetivos, para o autor, eram expor as existências negligenciadas. Por isso, eles liam os estudos sociais para conhecer os "homens de baixo" e as doenças sociais que os afetavam. Exemplo disso é o programa Federal "Writers Project" nos Estados Unidos, que, visando responder à crise social de 1929, encomendou trabalhos sobre os modos de vidas populares, fazendo com que a literatura assumisse uma função moral e política de ampliar perspectivas para o estabelecimento da democracia na sociedade americana.

Assim como a literatura, o jornalismo investigativo e o cinema, Rosanvallon sugere que as Ciências Sociais, no decurso do século XX, passaram a reconsiderar seus métodos e objetos de modo a oferecer uma análise dos "invisíveis" por meio de dimensões sociais e psicológicas. 
Michel de Certeau, Michel Foucault e Pierre Bourdieu são alguns dos autores que dissertaram sobre as vidas singulares ("vida dos infames" nos termos de Foucault) e a pluralidade de suas perspectivas e pontos de vista. Além desses, a Escola de Chicago, nos Estados Unidos, com Robert Parker, Erving Goffman e Howard Becker trabalharam em prol do reconhecimento intelectual da observação participante nos estudos da vida ordinária urbana, servindo de inspiração, por exemplo, para nova geração de sociólogos franceses que, em 2006, publicaram a obra coletiva A França Invisível. Não se limitando a uma perspectiva ocidentalizada, na Índia, por meio das Ciências Sociais e do campo da literatura, iniciou-se uma série de trabalhos que ligam relatos e representação política, como as autobiografias dos dalits, participantes do movimento das castas baixas no congresso indiano. Esses são apenas alguns exemplos que apontam formas de representação daqueles que foram historicamente marginalizados e excluídos e podem servir de inspiração para o projeto proposto pelo autor.

$\mathrm{Na}$ última parte do livro, Rosanvallon reitera a necessidade de contar o mundo por vias múltiplas: pelo jornalismo, pela literatura, pela etnografia, pela Sociologia, pela poesia etc. Pois, a partir dessas áreas, o mundo se torna sensível, devido às abordagens plurais de produção do conhecimento que, na era dos indivíduos, permitem decifrar o elo entre o singular e o geral. Sem hierarquizações e reconhecendo a importância de cada área, o projeto "Ranconter La Vie" almeja organizar suas atividades em busca da transdisciplinaridade e a pluralização dos modos de compreensão da realidade, reavaliando as modalidades do comum, explorando e cartografando as comunidades móveis que constituem o social.

Para isso, a organização das obras resultantes do projeto se dará, na visão de Rosanvallon, pelo conhecimento da escrita, da investigação e do testemunho, tendo uma função duplamente intelectual e democrática, na qual escritores, jornalistas, pesquisadores das Ciências Sociais e testemunhas poderão participar. O objetivo é produzir trabalhos a partir de pelo menos três conjuntos: (i) relatos e trajetórias de vida, que focam nas experiências; (ii) lugares de produção ou expressão do social - lugares de fluxo, não lugares, testemunho do mundo industrial etc.; (iii) momentos da vida - nascimento, casamento, desemprego ou recomeços. 
Para a execução e divulgação do projeto, o título do ensaio se baseia no site raconterlavie.fr, uma espécie de "facebook societário", que tem uma dupla função: ampliar o conteúdo e recepção dos livros e propor um espaço de discussão sobre as obras. A aposta é a de que o projeto, a partir da escrita de livros de histórias singulares e do site, apontará novas formas de representação que recuam na defesa de ideologia de identidade, mas que reconhece a realidade a partir do comum e da diversidade, servindo como luta contra o racismo, ideias populistas e o esvaziamento do sentido de povo. Desta maneira, "Raconter La Vie" "participa da refundação de uma democracia hoje perigosamente fragilizada" (ROSANVALLON, 2017, p.68).

Assim, em tempos nos quais as democracias de boa parte do mundo são ameaçadas por "ondas conservadoras" e "(pós)fascistas”, o ensaio de Pierre Rosanvallon contribui com uma reflexão essencial para a sustentação democrática. Trata-se, afinal, de uma perspectiva que reconhece a importância da abertura de discussões e a necessidade de ampliação de espaços alternativos de transformação, bem como discute seriamente a ampliação de formas de representação, que reconheçam que nem todos os campos são livres e que nem todos os grupos falam em nome da sociedade o tempo todo. Esse reconhecimento é o passo decisivo para que os "invisíveis" possam ser representados e se representem, tendo a oportunidade de participar de um lugar de formação de consciência social.

\section{REFERÊNCIAS BIBLIOGRÁFICAS:}

AB'SABER, Tales. Crise, Alucinose e Mentira: o Anticomunismo do nada brasileiro. Campinas: Editora da Unicamp, 2018.

COULDRY, Nick. Why Voice Matters: Culture And Politics Afer Neoliberalismo. Los Angeles: Sage, 2010.

ROSANVALLON, Pierre. O Parlamento Dos Invisiveis. São Paulo: Annablume Editora, 2017.

Texto recebido em 02/07/2019 e aprovado em 30/08/2019 
